\title{
Autologous Stem Cell Transplantation Is a Viable Postremission Therapy for Intermediate-Risk Acute Myeloid Leukemia in First Complete Remission in the Absence of a Matched Identical Sibling: A Meta-Analysis
}

\author{
Zhichao Li ${ }^{\mathrm{a}}$ Yinmei Liu ${ }^{\mathrm{b}}$ Qing Wang ${ }^{\mathrm{a}}$ Linjun Chen ${ }^{\mathrm{a}}$ Liyuan Ma ${ }^{\mathrm{a}}$ Siguo Hao \\ aDepartment of Hematology, Xinhua Hospital Affiliated to Shanghai Jiaotong University School of Medicine, \\ Shanghai, PR China; ${ }^{b}$ Department of Hospital Infection Management, Tenth People's Hospital of Tongji University, \\ Shanghai, PR China
}

\section{Keywords}

Allogeneic · Autologous - Transplantation - Acute myeloid leukemia $\cdot$ Intermediate risk $\cdot$ Meta-analysis

\begin{abstract}
Background: The preferred type of postremission therapy (PRT) for intermediate-risk acute myeloid leukemia (AML) in first complete remission (CR1) is a subject of continued debate. Although allogeneic stem cell transplantation (alloSCT) is regarded as a curative strategy for AML, the efficacy of autologous stem cell transplantation (autoSCT) for patients without a matched sibling donor (MSD) has remained controversial. Methods: To compare survival outcomes after alIoSCT versus autoSCT for patients with intermediate-risk AML in CR1, we performed a meta-analysis of 11 clinical studies. The outcomes included relapse-free survival (RFS), overall survival (OS), relapse rate (RR), and treatment-related mortality (TRM). Results: Compared with autoSCT, alloSCT showed better RFS, OS, and RR benefits, but higher TRM. Subgroup analysis based on donor category (MSD and matched unrelated donor [MUD]) of alloSCT showed alloSCT from MSD rather than from MUD had better OS benefits compared to autoSCT. For fms-like tyrosine kinase 3 internal tandem du-
\end{abstract}

plications (FLT3-ITD) wild-type patients, alloSCT and autoSCT had comparable RFS and OS outcomes. Conclusion: Our results suggest that, in the absence of an available MSD, autoSCT remains a viable PRT alternative for intermediate-risk $A M L$ in CR1, especially for FLT3-ITD wild-type patients.

(c) 2019 The Author(s)

Published by S. Karger AG, Basel

\section{Introduction}

Acute myeloid leukemia (AML) is a heterogeneous disease for which cytogenetic and molecular abnormalities at diagnosis are the most important prognostic factors and decide the course of postremission therapy (PRT) [1-3]. According to the guidelines of National Comprehensive Cancer Network (NCCN) [4], patients with AML can be divided into three risk status groups: good, intermediate, and poor risk. Patients with goodrisk AML are recommended to undergo high-dose cytarabine-based chemotherapy. Patients with poor-risk AML are recommended to undergo allogeneic stem cell transplantation (alloSCT). However, the best PRT for patients with intermediate-risk AML in first complete remission (AML/CR1) is still uncertain $[5,6]$. Currently,

\begin{tabular}{ll}
\hline KARGER & $\begin{array}{l}\text { @ } 2019 \text { The Author(s) } \\
\text { Published by S. Karger AG, Basel }\end{array}$ \\
E-Mail karger@karger.com & $\begin{array}{l}\text { This article is licensed under the Creative Commons Attribution- } \\
\text { NonCommercial-NoDerivatives 4.0 International License (CC BY- } \\
\text { NC-ND) (http://www.karger.com/Services/OpenAccessLicense). } \\
\text { Usage and distribution for commercial purposes as well as any dis- } \\
\text { tribution of modified material requires written permission. }\end{array}$
\end{tabular}

Siguo Hao

Department of Hematology

Xinhua Hospital Affiliated to Shanghai Jiaotong University School of Medicine

1665 Kongjiang Road, Shanghai 200092 (PR China)

E-Mail haosghj88@hotmail.com 
the choice of PRT comprises repeat cycles of consolidation chemotherapy, stem cell transplantation (autoSCT), and alloSCT [7].

In comparison with consolidation chemotherapy, autoSCT enables the administration of high-dose therapies supported by stem cell infusion, which leads to lower relapse rate $(R R)[8,9]$. Since the stem cell source shifted from bone marrow to peripheral blood, the treatment compliance of autoSCT has improved and the treatmentrelated mortality (TRM) has been reduced due to accelerated hematopoietic reconstitution $[8,10]$. In recent reports, autoSCT showed a higher long-term relapse-free survival (RFS) than that of chemotherapy in patients with AML/CR1 having intermediate cytogenetics $[6,8,9,11]$. The main disadvantages of autoSCT are the possibility of contamination of leukemic cells in the stem cell product [12] and the absence of graft-versus-leukemia effect, which lead to a higher RR than that of alloSCT.

Over the past 4 decades, alloSCT has proved to be a curative treatment for intermediate-risk AML. Metaanalyses of prospective clinical trials have shown that alloSCT from matched sibling donors (MSDs) provides significant RFS and overall survival (OS) benefits for patients with intermediate-risk AML/CR1, compared with non-alloSCT therapies $[13,14]$. However, these metaanalyses did not specifically investigate the cohort receiving only autoSCT. By contrast, other studies that compared alloSCT from MSDs or matched unrelated donors (MUDs) with autoSCT showed that there was no RFS or OS benefit for patients with intermediate-risk AML/CR1 [15-18]. Furthermore, although alloSCT is associated with a lower RR, it is still associated with higher incidences of TRM, graft-versus-host-disease and infections [19].

The lack of potential stem cell donors has long been a major limitation for using alloSCT. Fortunately, recent advances have greatly expanded the pool of alternative donor sources, including MUDs, haploidentical donors, and umbilical cord blood [20]. AutoSCT has become less popular. However, molecular makers (e.g., nucleophosmin 1 [NPM1] and fms-like tyrosine kinase 3 internal tandem duplications [FLT3-ITD]) [2], as well as minimal residual disease (MRD) status at the time of transplantation [21], have been shown to predict outcomes after different modes of PRT. Hence, we asked, in the current era, whether there was a role for autoSCT in the treatment of patients with intermediate-risk AML/CR1. To arrive at comprehensive estimates of the survival benefit from the totality of the data available, we performed a meta-analysis of all studies that compared alloSCT with autoSCT in patients with intermediate-risk AML/CR1.

Allogeneic versus Autologous SCT for Int-Risk AML/CR1

\section{Methods}

\section{Publication Search}

We searched the PubMed, Embase, and Cochrane Registry of Controlled Trials databases (updated March 2018), using the following terms: autologous; allogeneic; acut* and leukem*/leukaem*/ leucem*/leucaem*/aml; and myelo* or nonlympho*. The PubMed and Embase searches were restricted to adults, humans, and English language articles. We limited the publication type to comparative clinical studies. The titles, abstracts, and references lists were screened to identify eligible studies, and clearly nonrelevant articles were discarded. Recent reviews and meta-analysis were also assessed to identify other potentially eligible studies [13, 22, 23].

\section{Study Selection}

We included all published clinical studies of adults with intermediate-risk AML/CR1 that compared alloSCT with autoSCT with survival outcomes. The intermediate risk classification was defined by cytogenetic and molecular abnormalities. The outcomes were OS, RFS, TRM, and RR. When multiple articles were reported on the study, the most updated data were analyzed.

\section{Data Extraction}

Two authors independently extracted the data from the chosen studies using a prepiloted data collection form. The data collected included the following: first author, publication year, number of patients receiving alloSCT versus autoSCT, median patient age (years), median follow-up duration, stem cell source (bone marrow or peripheral blood), donor category of alloSCT (MSD or MUD), conditioning regimen, assessment criteria for intermediate-risk AML, and so on. We recorded the OS and RFS (also reported as disease-free survival, or leukemia-free survival) according to the individual studies. Data on TRM (also reported as nonrelapse mortality) and RR were also collected.

\section{Data Synthesis}

The meta-analysis was performed using STATA (version 12.0) software. The threshold of significance was $p<0.05$. Egger's test and funnel plots were used to investigate publication bias for RFS and OS outcomes. $I^{2}$ statistic was used to assess statistical heterogeneity, with $I^{2}>50 \%$ set as the cut-off to indicate significant result heterogeneity. Hazard ratios (HRs) and 95\% confidence intervals (CIs) were collected from each study. When HRs and CIs were not given in a paper, data were calculated by the method of Tierney et al. [24]. A forest plot with combined HRs (with 95\% CIs) for OS, RFS, TRM, and RR benefits of alloSCT versus autoSCT was constructed using fixed-effects analysis. In the subgroup analyses, we assessed OS and RFS benefits according to the donor category of alloSCT, that is, alloSCT from MSDs versus autoSCT and alloSCT from MUDs versus autoSCT. Tests of interactions across the subgroups were performed to evaluate whether the benefits of alloSCT varied significantly between the donor categories.

\section{Results}

\section{Study Searches/Selection}

Initial searches yielded 2,868 articles after removing duplicates (Fig. 1). No additional relevant studies were 
Fig. 1. Flow diagram of the studies in metaanalysis.

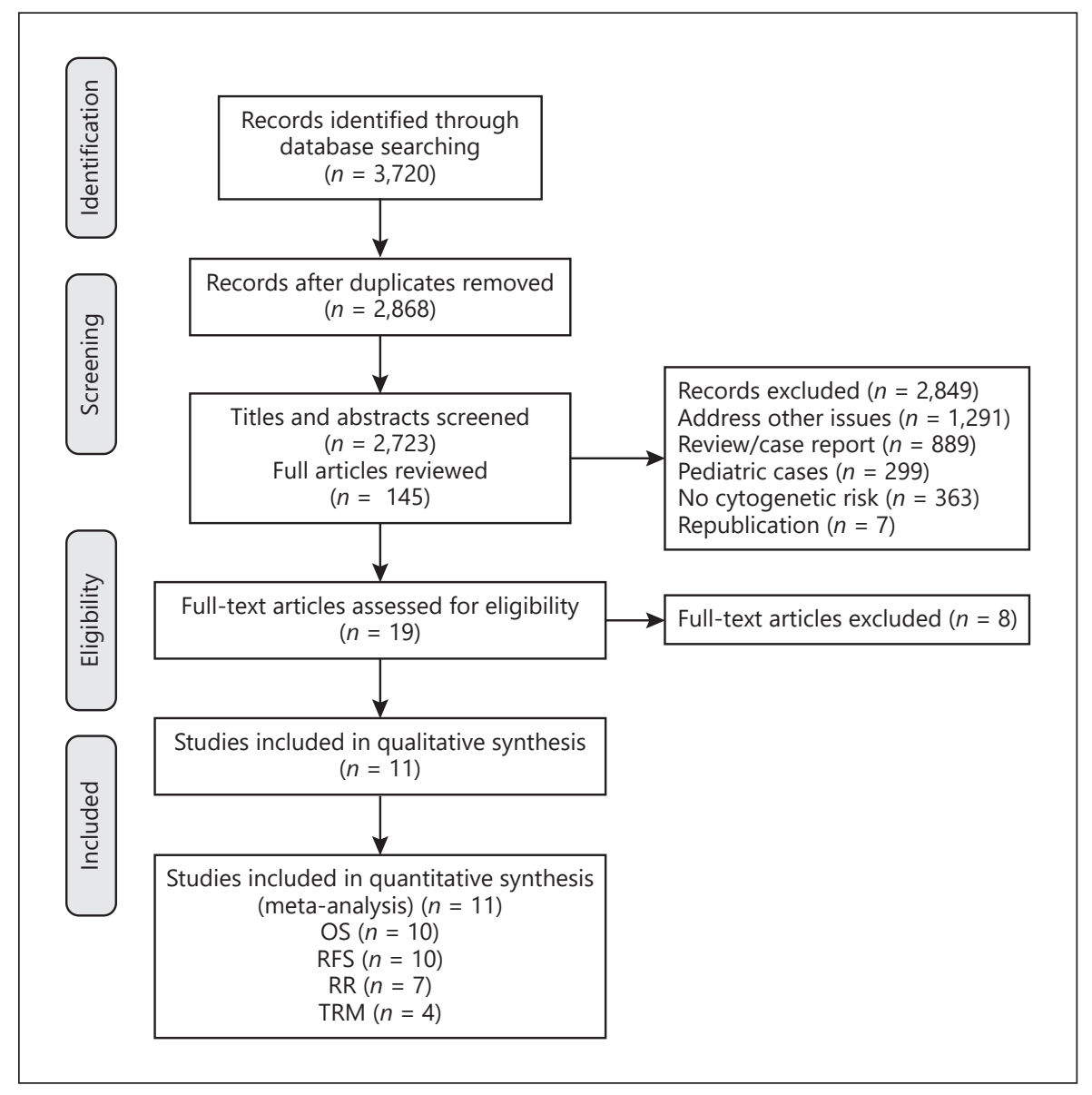

identified from recent review articles and meta-analyses. After screening, 2,849 articles were excluded on the basis of relevance, design, appropriate outcome data, and republications. The remaining 19 articles were retrieved for further review. Five studies [2, 14, 25-27] that evaluated alloSCT versus non-alloSCT therapies (consolidation chemotherapy and autoSCT) for patients with intermediate-risk AML/CR1 were excluded, because they did not perform a separate analysis on patients treated with autoSCT. One trial conducted by Pfirrmann et al. [6] was excluded as the authors used their own criteria rather than cytogenetic and molecular criteria to categorize the patient group. One study that compared autoSCT followed by immunotherapy with alloSCT for intermediaterisk AML/CR1 was excluded [28]. Another study that compared haploidentical transplantation with autoSCT was also excluded, since it was different from other studies using MSDs or MUDs as donor for alloSCT [29]. Finally, 11 clinical studies that compared the survival outcomes of alloSCT and autoSCT for intermediate-risk AML/CR1 were selected.

\section{Study Characteristics}

The characteristics of the 11 included studies are summarized in Tables 1 and 2. The median sample size was 254 patients (range $80-1,133$ ). It is noted that the standard characteristics of intermediate-risk AML consist of cytogenetic and molecular abnormalities. The cytogenetic criteria used in different studies are substantially similar, that is, intermediate-risk cytogenetic abnormalities include normal cytogenetics, +8 , and all other cytogenetic abnormalities. Molecular abnormalities including FLT3ITD and NPM1 mutations can further refine cytogenetically normal AML. FLT3-ITD mutations are associated with an unfavorable prognosis, whereas NPM1 mutations in the absence of FLT3-ITD are associated with a relatively favorable outcome [4]. Four of the included studies provided data on FLT3-ITD and NPM1. In one study [30], patients with wild-type NPM1(NPM1 $\left.{ }^{\mathrm{wt}}\right)$ without FLT3-ITD or with a low allelic burden of FLT3-ITD $(<0.5)$ were considered as intermediate-risk group because of similar OS and RFS at 5 years. In the other 3 studies, their intermediate-risk AML were FLT3-ITD 
Table 1. Summary of studies evaluating alloSCT versus autoSCT in patients with intermediate-risk AML/CR1

\begin{tabular}{|c|c|c|c|c|c|c|c|c|c|c|}
\hline $\begin{array}{l}\text { First author [Ref.], } \\
\text { year of publication }\end{array}$ & $\begin{array}{l}\text { Transplanta- } \\
\text { tion period }\end{array}$ & alloSCT & autoSCT & alloSCT & autoSCT & $\begin{array}{l}\text { Median } \\
\text { follow-up, } \\
\text { months } \\
\text { (range) }\end{array}$ & RFS & OS & $\mathrm{RR}$ & TRM \\
\hline Slovak [1], 2000 ${ }^{\mathrm{a}}$ & 1990-1995 & 47 & 37 & $34(18-54)$ & $39(16-55)$ & $57.6(8-90)$ & NR & no & NR & NR \\
\hline Suciu [33], 2003 & 1993-1999 & 61 & 104 & $35(15-45)$ & $33(15-45)$ & 48 (NR) & no & no & no & no \\
\hline Cho [34], 2013 & $2002-2009$ & 199 & 89 & $36(16-65)$ & $42(15-65)$ & $74(6-120)$ & yes & no & no & NR \\
\hline Saraceni [32], 2016 & 2005-2013 & 217 & 120 & $48(18-76)$ & $46(18-78)$ & 36 (NR) & no & no & yes & no \\
\hline Mizutani [18], 2016 & 1995-2011 & 565 & 231 & $40(16-74)$ & $47(17-80)$ & $60(\mathrm{NR})$ & no & NR & NR & NR \\
\hline Versluis [30], 2017 & $1995-2010$ & 142 & 104 & $49(16-60)$ & $48(16-61)$ & 77 (NR) & no & no & yes & no \\
\hline Gorin [17], 2017 & 2005-2015 & 93 & 52 & NR & NR & 29 (NR) & no & no & no & no \\
\hline Mizutani [35], 2017 & 1995-2011 & 173 & 177 & $39(30-50)$ & $49(39-57)$ & $43(16-60)$ & no & no & yes & $\mathrm{NR}$ \\
\hline
\end{tabular}

alloSCT, allogeneic stem cell transplantation; autoSCT, autologous stem cell transplantation; AML, acute myeloid leukemia; CR1, first complete remission; RFS, relapse-free survival; OS, overall survival; RR, relapse rate; TRM, treatment-related mortality; NR, not reported. ${ }^{a}$ Prospective.

Table 2. Stem cell source, donor category, and conditioning regimen of studies

\begin{tabular}{|c|c|c|c|c|c|}
\hline $\begin{array}{l}\text { First author [Ref.], year } \\
\text { of publication }\end{array}$ & \multicolumn{2}{|c|}{ Stem cell source } & Donor category & \multicolumn{2}{|l|}{ Conditioning regimen } \\
\hline Suciu [33], 2003 & $\mathrm{BM}$ & $\mathrm{BM}, \mathrm{PB}$ & MSD & Cy+TBI (12 Gy); Bu+Cy & Cy+TBI (12 Gy); Bu+Cy \\
\hline Cho [34], 2013 & $\mathrm{BM}, \mathrm{PB}$ & $\mathrm{PB}$ & MUD, MSD & $\begin{array}{l}\text { MAC: } \mathrm{Cy}+\mathrm{TBI}, \mathrm{Bu}+\mathrm{Cy} \\
\text { TBI+Ara-C+Mel; RIC: } \\
\text { Flu+Bu }\end{array}$ & TBI (12 Gy)+Ara-C+Mel \\
\hline Keating [16], 2013 & $\mathrm{BM}, \mathrm{PB}$ & $\mathrm{PB}$ & MSD & $\mathrm{NA}^{\mathrm{a}}$ & NR \\
\hline Cornelissen [9], 2015 & NR & $\mathrm{PB}$ & MSD, MUD & $\begin{array}{l}\text { MAC: Cy+TBI (12 Gy), } \\
\text { Bu+Cy; } \\
\text { RIC: Flu+TBI ( } 2 \text { Gy) }\end{array}$ & $\mathrm{Bu}+\mathrm{Cy}$ \\
\hline Gorin [17], 2017 & $\mathrm{~PB}, \mathrm{BM}$ & $\mathrm{PB}$ & MUD & $\mathrm{Bu}+\mathrm{Cy}, \mathrm{Bu}+\mathrm{Flu}$ & $\mathrm{Bu}+\mathrm{Cy}, \mathrm{Bu}+\mathrm{Mel}$ \\
\hline Mizutani [35], 2017 & $\mathrm{BM}$ & $\mathrm{PB}$ & MUD & NR & $\mathrm{NA}^{\mathrm{c}}$ \\
\hline Yao [31], 2017 & $\mathrm{~PB}$ & $\mathrm{~PB}, \mathrm{BM}$ & MSD, MUD & $\begin{array}{l}\mathrm{Bu}+\mathrm{Cy}+\mathrm{Flu}+\mathrm{Ara}-\mathrm{C} \\
\mathrm{Bu}+\mathrm{Flu}+\mathrm{Ara}-\mathrm{C}\end{array}$ & $\begin{array}{l}\mathrm{Bu}+\mathrm{Cy}+\mathrm{Flu}+\mathrm{Ara}-\mathrm{C} \\
\mathrm{Bu}+\text { Flu+Ara-C }\end{array}$ \\
\hline
\end{tabular}

BM, bone marrow; PB, peripheral blood; MSD, matched sibling donor; MUD, matched unrelated donor; BU, busulfan; Cy, cyclophosphamide; TBI, total body irradiation; MAC, myeloablative conditioning; RIC, reduced-intensity conditioning; Mel, melphalan; Ara-C, cytarabine; Flu, fludarabine; NR, not reported; NA, not applicable. ${ }^{a}$ All patients used MAC regimen followed by alloSCT. ${ }^{b}$ Either MAC or RIC was used as regimen of alloSCT. ${ }^{c}$ In this study, $77 \%$ patients received a conditioning regimen containing high-dose cytarabine followed by autoSCT. 
Table 3. Intermediate risk criteria of studies

\begin{tabular}{|c|c|c|c|}
\hline $\begin{array}{l}\text { First author [Ref.], } \\
\text { publication year }\end{array}$ & $\begin{array}{l}\text { Multi- } \\
\text { center }\end{array}$ & $\begin{array}{l}\text { Standard } \\
\text { criteria }\end{array}$ & Intermediate risk inclusion \\
\hline Slovak [1], 2000 & yes & SWOG & $\mathrm{NK},+8,+6,-\mathrm{Y}, \operatorname{del}(12 \mathrm{p})$ \\
\hline Suciu [33], 2003 & yes & ISCN & $\mathrm{NK},-\mathrm{Y}$ \\
\hline Cho [34], 2013 & no & revised MRC & Cytogenetic abnos not classified as favorable or adverse \\
\hline Keating [16], 2013 & yes & SWOG & $\mathrm{NK},+8,+21, \mathrm{t}(1 ; 7), \mathrm{t}(8 ; 16)$, other abnos \\
\hline Cornelissen [9], 2015 & yes & ELN & NK, $\mathrm{t}(9 ; 11)(\mathrm{p} 22 ; \mathrm{q} 23)$, other abnos \\
\hline Saraceni [32], 2016 & yes & ELN & NK:FLT3-ITD ${ }^{w t}$ and NPM1 ${ }^{\text {wt }}$ \\
\hline Mizutani [18], 2016 & yes & NCCN-2014 & NK, +8 alone, $\mathrm{t}(9 ; 11)$, other abnos \\
\hline Versluis [30], 2017ª & yes & NR & $\begin{array}{l}\text { NK:NPM1 } 1^{\text {wt }} \text { and FLT3-ITD }{ }^{\text {wt }} \text { or low FLT3-ITD allelic } \\
\text { ratio }(<0.5)\end{array}$ \\
\hline Gorin [17], 2017 & yes & ELN & $\begin{array}{l}\mathrm{t}(9 ; 11)(\mathrm{p} 22 ; \mathrm{q} 23), \text { cytogenetic abnos not classified as } \\
\text { favorable or adverse }\end{array}$ \\
\hline Mizutani [35], 2017 & yes & NCCN-2014 & NK \\
\hline Yao [31], 2017 & no & NCCN-2015 & $\begin{array}{l}\text { NK:FLT3-ITD }{ }^{\mathrm{wt}} \text { and NPM1 }{ }^{\mathrm{wt}} ;+8 \text { alone, } \mathrm{t}(9 ; 11) \text {, other } \\
\text { abnos; } \mathrm{t}(8 ; 21), \operatorname{inv}(16), \mathrm{t}(16 ; 16): \mathrm{c}-\mathrm{KIT}^{\mathrm{mut}}\end{array}$ \\
\hline
\end{tabular}

SWOG, South West Oncology Group; ISCN, International System for Cytogenetic Nomenclature; MRC, Medical Research Council; ELN, European LeukemiaNET; NCCN, National Comprehensive Cancer Network; FLT3-ITD, fms-like tyrosine kinase 3 internal tandem duplications; NPM1, nucleophosmin 1; NK, normal karyotype; abnos, abnormalities; mut, mutant; wt, wild-type; NR, not reported. ${ }^{a}$ This study was divided into FLT3-ITD ${ }^{\text {wt }}$ group, as patients with FLT3-ITD ${ }^{\text {wt }}$ or with low FLT3-ITD allelic ratio $(<0.5)$ had similar outcomes. ${ }^{\mathrm{b}}$ Only intermediate-2 patients were included, as intermediate-1 group contained all patients who were FLT3ITD $^{\text {mut }}$.

wild-type (FLT3-ITD ${ }^{\mathrm{wt}}$ ) and NPM1 ${ }^{\mathrm{wt}}[17,31,32]$. On the basis of whether data on FLT3-ITD were available or not, we divided the included studies into two subgroups: FLT3-ITD ${ }^{\text {wt }}$ and FLT3-ITD unknown (FLT3-ITD ${ }^{\text {uk }}$ ). Relevant subgroup analyses were conducted to evaluate the RFS and OS outcomes of alloSCT versus autoSCT. The intermediate risk criteria of each study are summarized in Table 3.

\section{Relapse-Free Survival}

RFS data were available for 10 studies. The interstudy heterogeneity was nonsignificant $(p=0.138)$, with $I^{2}=$ $33.8 \%$. In a fixed-effects forest plot, the combined HR for RFS was 0.82 (95\% CI: 0.73-0.92), indicating that alloSCT significantly reduced the incidence of death or relapse in intermediate-risk AML/CR1 (Fig. 2a). We further evaluated the studies with subgroup analyses. Four studies used MSDs as donor for alloSCT (group 1), 4 studies used MUDs (group 2) (one study [34] used MSDs and MUDs separately), and 3 studies used MSDs or MUDs (group 3 ).
Subgroup meta-analysis based on donor category showed an RFS benefit with alloSCT in groups 2 and 3 (HR: 0.74, 95\% CI: 0.57-0.97; and HR: 0.69, 95\% CI: 0.53-0.91, respectively; Fig. 2b). A trend was found toward an RFS benefit with alloSCT in group 1 (HR: 0.86, 95\% CI: $0.74-$ 1.00; Fig. 2b). A test of the interactions among the three groups was not significant. We subsequently evaluated RFS outcomes according to FLT3-ITD status. FLT3-IT$\mathrm{D}^{\mathrm{wt}}$ AML had a combined HR of 0.77 (95\% CI: 0.58-1.03) across 4 studies, indicating a lack of RFS benefit with alloSCT (Fig. 2a). FLT3-ITD ${ }^{\text {uk }}$ AML had a combined HR of 0.83 (95\% CI: 0.73-0.94) across 6 studies, indicating a significant RFS benefit with alloSCT (Fig. 2a).

\section{Overall Survival}

Ten studies reported intermediate-risk AML data for OS. Of note, none of the 10 studies showed significantly different OS between the alloSCT and autoSCT recipients. The interstudy heterogeneity was nonsignificant $(p=0.81)$, with $I^{2}=0.0 \%$. In a fixed-effects forest plot, the 


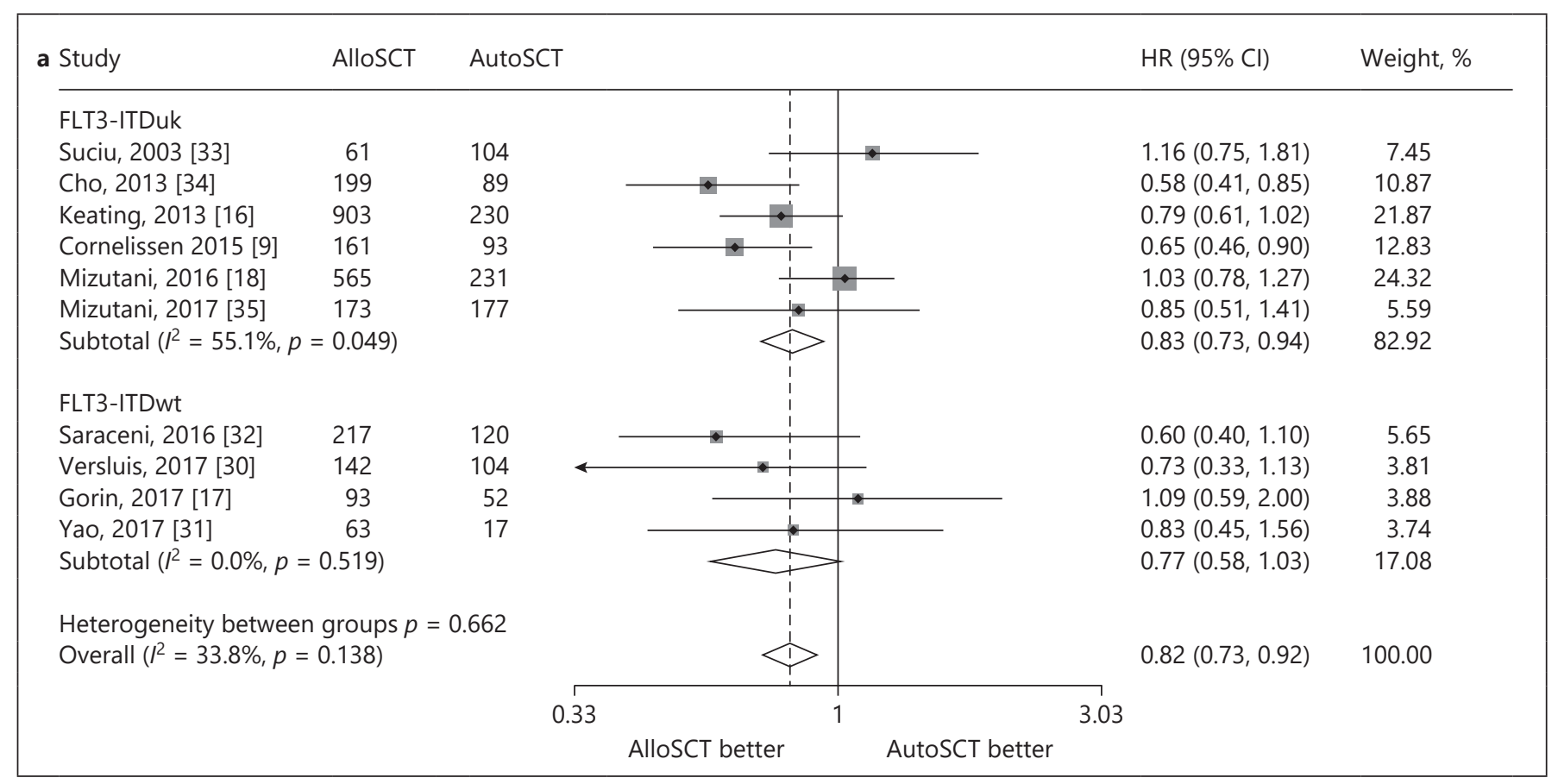

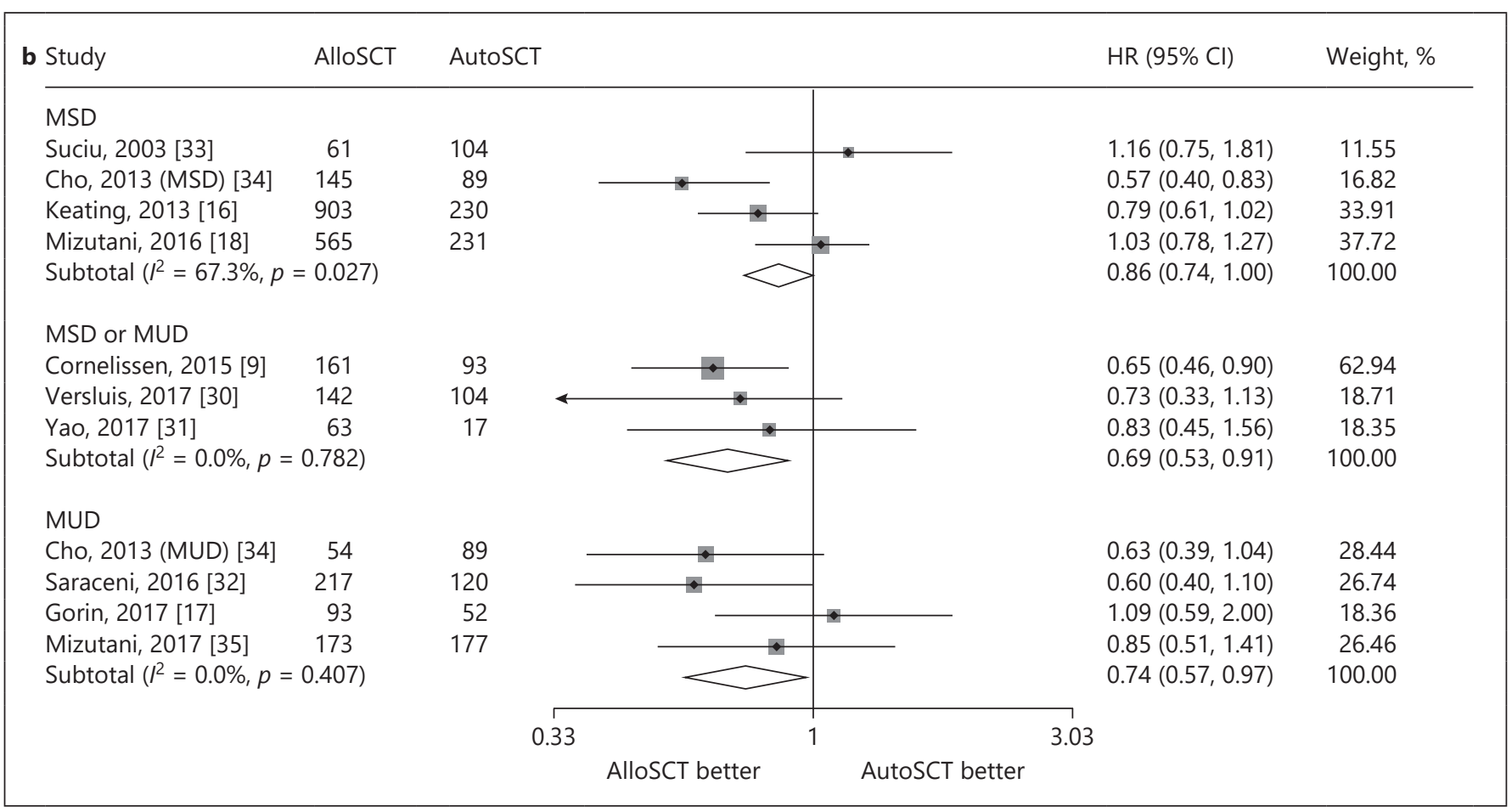

Fig. 2. Forest plot of the RFS benefit of alloSCT in intermediate-risk AML/CR1. a Forest plot of the overall RFS benefit and the subgroup RFS benefit based on FLT3-ITD status. b Forest plot of the subgroup RFS benefit based on donor category of alloSCT. 


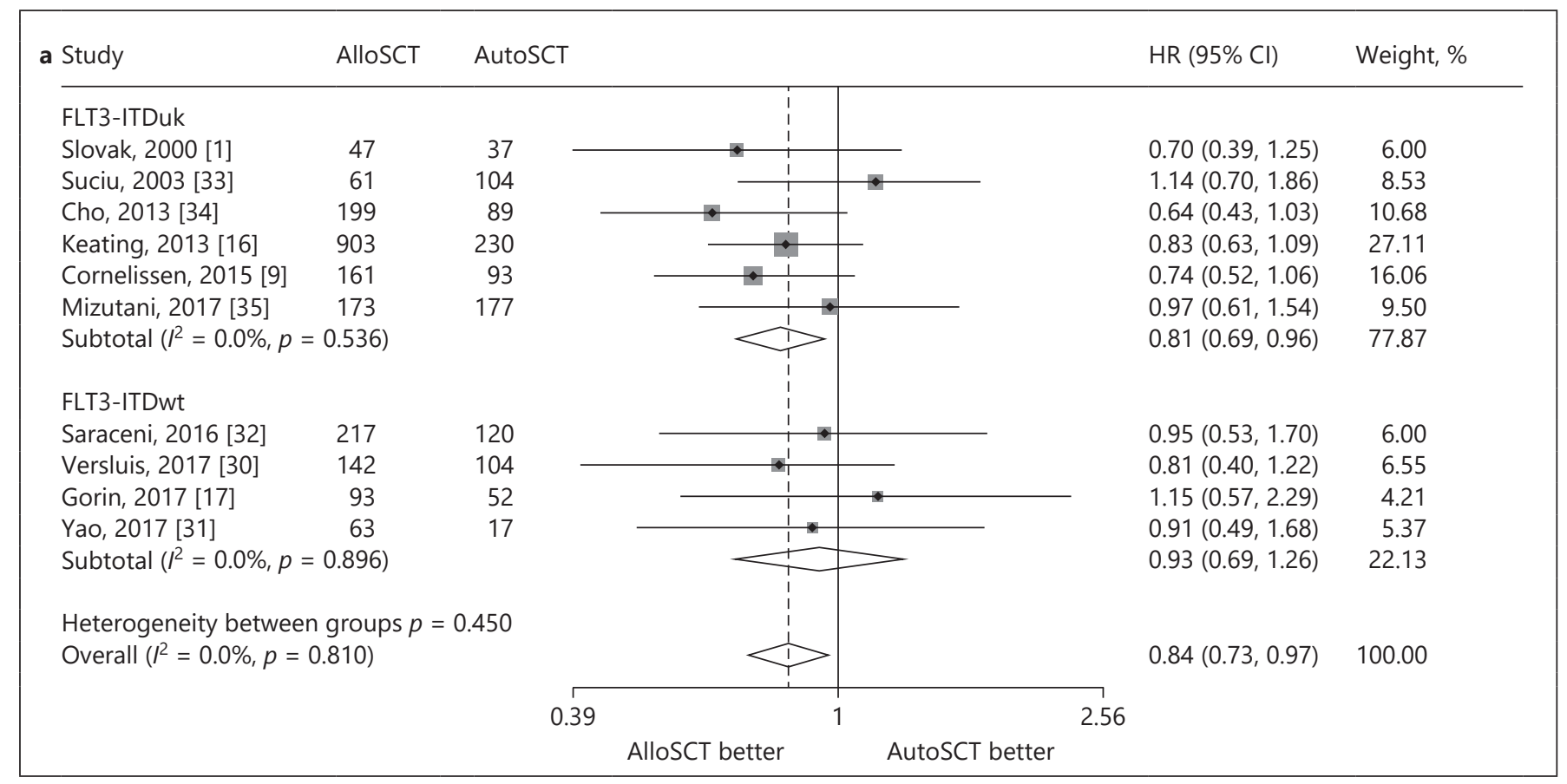

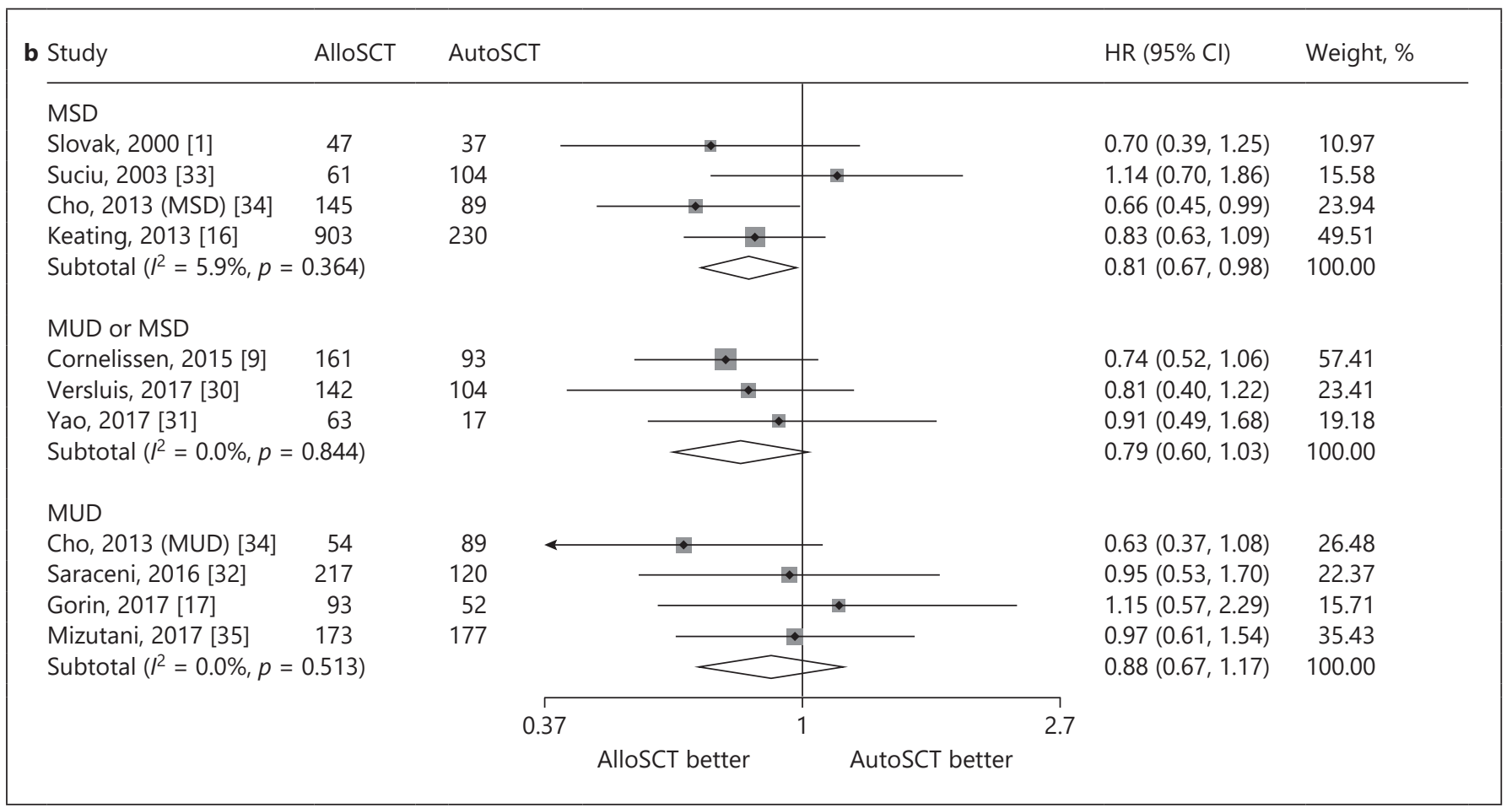

Fig. 3. Forest plot of the OS benefit of alloSCT in intermediate-risk AML/CR1. a Forest plot of the overall OS benefit and the subgroup OS benefit based on FLT3-ITD status. b Forest plot of the subgroup OS benefit based on donor category of alloSCT. 


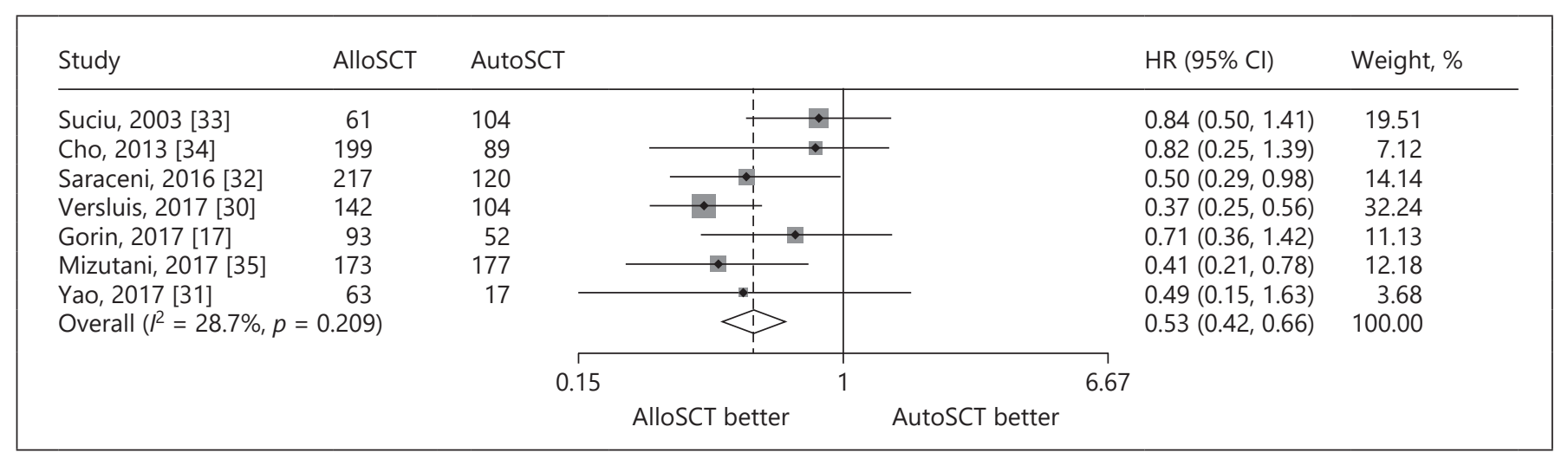

Fig. 4. Forest plot of the RR benefit of alloSCT in intermediate-risk AML/CR1.

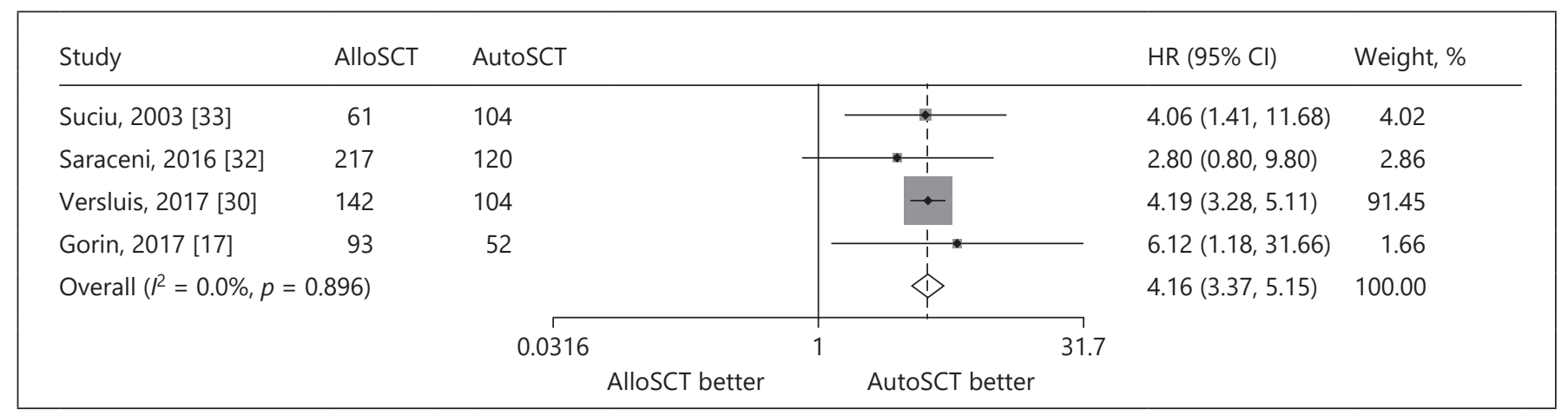

Fig. 5. Forest plot of the TRM benefit of alloSCT in intermediate-risk AML/CR1.

combined HR for OS benefit with alloSCT was 0.84 (95\% CI: 0.73-0.97), indicating a statistically significant reduction in the hazard of death with alloSCT (Fig. 3a). We further evaluated the studies with subgroup analyses. According to the donor category of alloSCT, 4 studies used MSDs (group 1), 4 studies used MUDs (group 2) (one study [34] used MSDs and MUDs separately), and 3 studies used MSDs or MUDs (group 3). Relevant subgroup analyses showed an OS benefit with alloSCT in group 1, but not in groups 2 and 3 (HR: 0.81, 95\% CI: 0.67-0.98; HR: 0.88, 95\% CI: 0.67-1.17; and HR: 0.79, 95\% CI: 0.60 1.03 , respectively), indicating that compared with autoSCT, alloSCT from MSDs rather than from MUDs had a better OS benefit (Fig. 3b). A test of interactions among the three groups was not significant. We also evaluated OS outcomes by FLT3-ITD status. FLT3-ITD ${ }^{\text {wt }}$ AML had a combined HR of 0.93 (95\% CI: 0.69-1.26) across 4 studies, indicating a lack of OS benefit with alloSCT (Fig. 3a). FLT3-ITD $^{\text {uk }}$ AML had a combined HR of 0.81 (95\% CI:
0.69-0.96) across 6 studies, indicating a significant OS benefit with alloSCT (Fig. 3a).

\section{Relapse Rate}

Seven studies reported intermediate-risk AML data for RR. The interstudy heterogeneity was nonsignificant $(p=0.209)$, with $I^{2}=28.7 \%$. In a fixed-effects forest plot, the overall HR was 0.53 (95\% CI: 0.42-0.66). This outcome indicated that alloSCT significantly reduced the relapse of intermediate-risk AML compared with autoSCT (Fig. 4).

\section{Treatment-Related Mortality}

Four studies reported intermediate-risk data for TRM. The interstudy heterogeneity was nonsignificant $(p=$ 0.896 ), with $I^{2}=0.0 \%$. In a fixed-effects forest plot, the overall HR was 4.16 (95\% CI: 3.37-5.15), indicating that the alloSCT group had higher non-relapse-related mortality than the autoSCT group did (Fig. 5). 


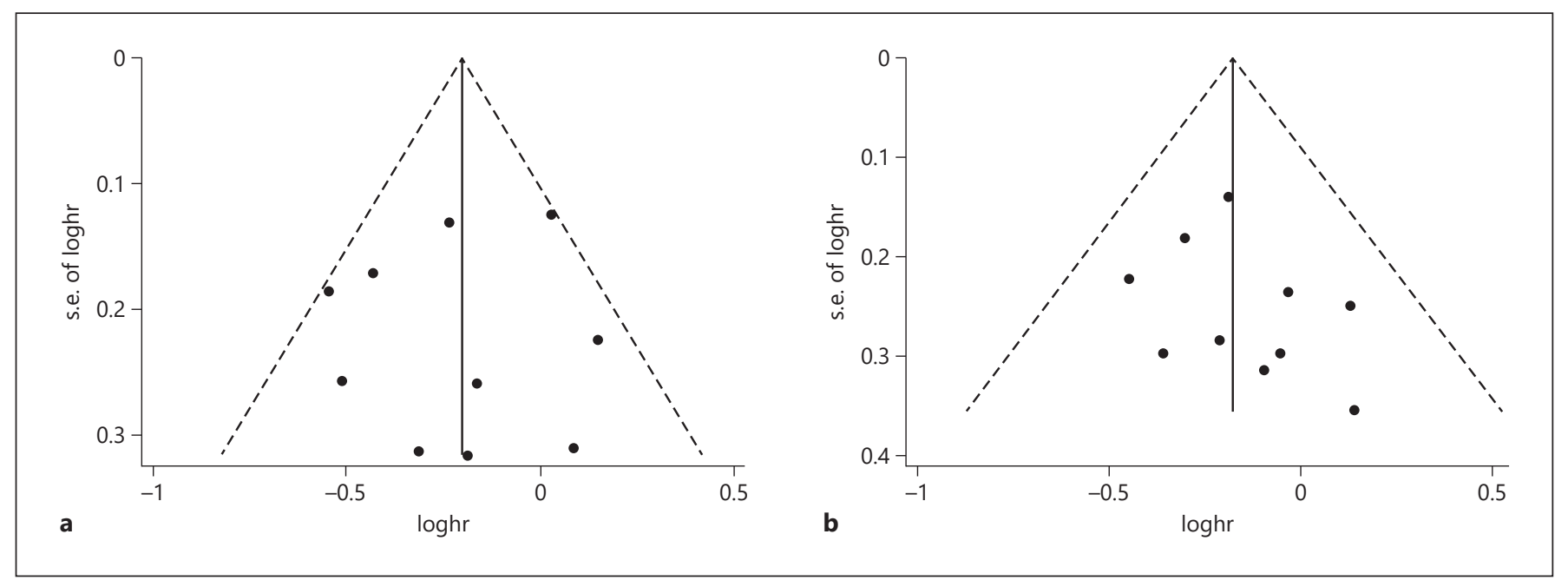

Fig. 6. Funnel plot for publication bias test. a Relapse-free survival. b Overall survival.

\section{Publication Bias}

Egger's test was performed to access the publication bias in the literature. All studies investigating RFS yielded an Egger's test score of $p=1.0$, indicating that there was no significant difference in publication bias for RFS. A similar result was found for OS $(p=0.283)$. The funnel plot also suggested that there was no publication bias for RFS and OS (Fig. 6).

\section{Discussion}

Intermediate-risk AML accounts for $60-70 \%$ of all cases of AML [13] and represents the gray zone for transplantation guidelines. Earlier donor versus no-donor studies evidenced a survival benefit with alloSCT over non-alloSCT therapies for intermediate-risk AML [13, 14]. Nevertheless, the donor versus no-donor analyses suffered from biologic randomization bias. Furthermore, most studies combined patients receiving autoSCT and conventional chemotherapy into the no-donor arm and included mostly young patients that received grafts from MSDs. With the advent of alternative donors (MUDs, haploidentical donors, and umbilical cord blood), donor versus no-donor studies have become obsolete. In some recent retrospective observations, autoSCT has been shown to provide similar survival to that of allo-SCT from MSDs and MUDs [16-18].

Hence, we conducted a meta-analysis to compare survival outcomes of alloSCT from MSDs or MUDs versus
autoSCT in intermediate-risk AML and demonstrated that alloSCT from MSDs rather than MUDs was associated with better OS than that with autoSCT, despite the RFS benefit of alloSCT using MUDs. Only one study comparing haploidentical-SCT with autoSCT was found [29]. In this study, the OS was significantly higher following autoSCT than haploidentical-SCT in intermediate-risk AML (71 vs. $58 \%, p=0.03$ ). We did not find any study comparing umbilical cord blood transplantation with autoSCT.

The major obstacle associated with autoSCT is the higher RR due to lack of graft-versus-leukemia effect and possibility of contamination of leukemic cells in the stem cell product [12], although this can be counteracted partially by a lower TRM after autoSCT, as supported in the present study. For cytogenetically normal AML, which constitutes the majority of intermediate-risk AML [36], molecular markers such as NPM1 and FLT3-ITD have been shown to provide additional prognostic information on RR [2]. Although patients with NPM1 mutations have an improved outcome with chemotherapy alone, FLT3ITD mutations may negate the favorable prognosis of the NPM1 mutations and the outcome is poorer than when NPM1 is mutated and FLT3-ITD is germline [2, 37]. Many researches have reported that alloSCT can improve the survival outcomes for FLT3-ITD ${ }^{\text {mut }}$ AML [38-40]. The subgroup analysis of the present study indicates that alloSCT and autoSCT have comparable outcomes for FLT3-ITD ${ }^{\text {wt }}$ AML, whereas alloSCT has better outcomes than autoSCT for FLT3-ITD ${ }^{\text {uk }}$ AML, of which some patients may be FLT3-ITD ${ }^{\text {mut }}$. 
In addition to molecular markers, the MRD status assessed by flow cytometry or molecular analysis is another vital prognostic factor. A series of studies demonstrated that MRD negativity at transplant was strongly correlated with better outcomes and had independent prognostic value [41-45]. Of the included studies in the current meta-analysis, 2 studies provided data on MRD status. In one European Society for Blood and Marrow Transplantation registry study [17] that compared alloSCT using MUDs with autoSCT, all patients were tested to be MRDnegative (molecular CR). According to European LeukemiaNet classification, patients were divided into favorable, intermediate- 1 , and intermediate- 2 groups. In the favorable group, autoSCT was associated with a better OS than alloSCT was ( 83 vs. $62 \%, p=0.008)$. In the intermediate-2 group, there was no significant difference between autoSCT and alloSCT outcomes for RFS (60 vs. 64\%, $p=$ 0.8 ) and OS ( 74.5 vs. $70.6 \%, p=0.94)$. In the intermediate-1 group, which included AML with FLT3-ITD ${ }^{\text {mut }}$, autoSCT was inferior to alloSCT for RFS ( 39 vs. $70 \%, p<$ $10^{-6}$ ) and OS (61 vs. $74 \%, p=0.005$ ). In the other study [31], patients were stratified on the basis of cytogenetic and molecular abnormalities as well as MRD status. For patients with favorable and intermediate risks and negative MRD after one course of consolidation chemotherapy, autoSCT and alloSCT offered comparable outcomes; otherwise, autoSCT was inferior owing to a higher risk of leukemia relapse. All these results above support the conclusion that autoSCT may be suitable for patients with AML without MRD and adverse-risk molecular markers.

There are several limitations to our analysis. First, except for 2 prospective clinical trials, the rest of the studies were retrospective in nature with great inherent risk of bias, which should prompt us to interpret the results of the present meta-analysis with caution. Second, there were problems concerning the variety of different pretransplant conditioning regimens. Either myeloablative conditioning (MAC) or reduced-intensity conditioning (RIC) regimens were used before alloSCT. A meta-analysis published by Wahid et al. [46] showed that there was no OS benefit with MAC over RIC regimens. However, for autoSCT, several reports showed that a high-dose cytarabine-containing regimen provided a favorable longterm RFS of $61-71 \%[35,47]$. The pretransplant conditioning regimens are summarized in Table 2. Finally, owing to the limited follow-up period (the median follow-up of the included studies was 57.6 months), we did not have information on the late recurrence rates, especially after autoSCT. Disease recurrence occurs mainly during the first 2 years after autoSCT, and therefore patients who survive free of disease recurrence after this period are considered to have a good prognosis [8]. However, Czerw et al. [48] conducted a study showing that cumulative incidence of relapse at 10 years was $16 \%$ for patients with AML who remained free of disease recurrence at least 2 years after autoSCT. Although these patients were easily rescued by alloSCT [49], the result indicated the need for close monitoring MRD and additional leukemic control measures after autoSCT.

In summary, the present meta-analysis shows that in the absence of an available MSD, autoSCT remains a promising choice as PRT for patients with intermediaterisk AML/CR1. The absence of FLT3-ITD ${ }^{\text {mut }}$ and MRD may favor the use of autoSCT over alloSCT with respect to ensuring the quality of life as well as comparable survival outcomes, and alloSCT from an alternative donor can be used to rescue patients who relapse after autoSCT. Our study may justify the reconsideration of randomized studies including autoSCT in patients with intermediaterisk AML/CR1, especially in the context of posttransplant immune-mediated cell therapy that may target clonogenic leukemic cells [50].

\section{Statement of Ethics}

There are no ethical requirements for this article, because a meta-analysis is a secondary study based on the results of other authors' research.

\section{Disclosure Statement}

The authors declare no conflicts of interest.

References

1 Slovak ML, Kopecky KJ, Cassileth PA, Harrington $\mathrm{DH}$, Theil KS, Mohamed $\mathrm{A}$, et al. Karyotypic analysis predicts outcome of preremission and postremission therapy in adult acute myeloid leukemia: a Southwest Oncology Group/Eastern Cooperative Oncology Group Study. Blood. 2000 Dec;96(13):4075-83.

2 Schlenk RF, Döhner K, Krauter J, Fröhling S, Corbacioglu A, Bullinger L, et al.; GermanAustrian Acute Myeloid Leukemia Study Group. Mutations and treatment outcome in cytogenetically normal acute myeloid leukemia. N Engl J Med. 2008 May;358(18):190918.

3 Patel JP, Gönen M, Figueroa ME, Fernandez $\mathrm{H}$, Sun Z, Racevskis J, et al. Prognostic relevance of integrated genetic profiling in acute myeloid leukemia. N Engl J Med. 2012 Mar; 366(12):1079-89. 
4 National Comprehensive Cancer Network. Acute myeloid leukemia, Version 3. 2017 [accessed 2018 Jan 3]. Available from http:// www.nccn.org/.

5 Burnett AK, Goldstone A, Hills RK, Milligan D, Prentice A, Yin J, et al. Curability of patients with acute myeloid leukemia who did not undergo transplantation in first remission. J Clin Oncol. 2013 Apr;31(10):1293301.

6 Pfirrmann M, Ehninger G, Thiede C, Bornhäuser M, Kramer M, Röllig C, et al.; Study Alliance Leukaemia (SAL). Prediction of post-remission survival in acute myeloid leukaemia: a post-hoc analysis of the AML96 trial. Lancet Oncol. 2012 Feb;13(2):207-14.

7 Schlenk RF. Post-remission therapy for acute myeloid leukemia. Haematologica. 2014 Nov; 99(11):1663-70.

8 Vellenga E, van Putten W, Ossenkoppele GJ, Verdonck LF, Theobald M, Cornelissen JJ, et al.; Dutch-Belgian Hemato-Oncology Cooperative Group (HOVON); Swiss Group for Clinical Cancer Research Collaborative Group (SAKK). Autologous peripheral blood stem cell transplantation for acute myeloid leukemia. Blood. 2011 Dec;118(23):6037-42.

9 Cornelissen JJ, Versluis J, Passweg JR, van Putten WL, Manz MG, Maertens J, et al.; HOVON; SAKK Leukemia Groups. Comparative therapeutic value of post-remission approaches in patients with acute myeloid leukemia aged 40-60 years. Leukemia. 2015 May; 29(5):1041-50.

10 Vellenga E, van Putten WL, Boogaerts MA, Daenen SM, Verhoef GE, Hagenbeek A, et al. Peripheral blood stem cell transplantation as an alternative to autologous marrow transplantation in the treatment of acute myeloid leukemia? Bone Marrow Transplant. 1999 Jun;23(12):1279-82.

11 Herrera DA, Mudiyanselage NG, Gaudel P, et al. Autologous transplantation is associated with better outcomes compared to chemotherapy alone in a minority-rich non-highrisk acute myeloid leukemia cohort. Blood. 2017; 130:3293.

12 Gorin NC, Labopin M, Blaise D, Reiffers J, Meloni G, Michallet M, et al.; Acute Leukemia Working Party of the European Cooperative Group for Blood and Marrow Transplantation. Higher incidence of relapse with peripheral blood rather than marrow as a source of stem cells in adults with acute myelocytic leukemia autografted during the first remission. J Clin Oncol. 2009 Aug;27(24):3987-93.

13 Koreth J, Schlenk R, Kopecky KJ, Honda S, Sierra J, Djulbegovic BJ, et al. Allogeneic stem cell transplantation for acute myeloid leukemia in first complete remission: systematic review and meta-analysis of prospective clinical trials. JAMA. 2009 Jun;301(22):2349-61.
14 Cornelissen JJ, van Putten WL, Verdonck LF, Theobald M, Jacky E, Daenen SM, et al. Results of a HOVON/SAKK donor versus nodonor analysis of myeloablative HLA-identical sibling stem cell transplantation in first remission acute myeloid leukemia in young and middle-aged adults: benefits for whom? Blood. 2007 May; 109(9):3658-66.

15 Herr AL, Labopin M, Blaise D, Milpied N, Potter M, Michallet M, et al.; Acute Leukemia Working Party or the European Group for Blood and Marrow Transplantation. HLAidentical sibling allogeneic peripheral blood stem cell transplantation with reduced intensity conditioning compared to autologous peripheral blood stem cell transplantation for elderly patients with de novo acute myeloid leukemia. Leukemia. 2007 Jan;21(1):129-35.

16 Keating A, DaSilva G, Pérez WS, Gupta V, Cutler CS, Ballen KK, et al. Autologous blood cell transplantation versus HLA-identical sibling transplantation for acute myeloid leukemia in first complete remission: a registry study from the Center for International Blood and Marrow Transplantation Research. Haematologica. 2013 Feb;98(2):185-92.

17 Gorin NC, Labopin M, Pabst T, Remenyi P, Wu D, Huynh A, et al.; Acute Leukemia Working Party of the EBMT. Unrelated matched versus autologous transplantation in adult patients with good and intermediate risk acute myelogenous leukemia in first molecular remission. Am J Hematol. 2017 Dec; 92(12):1318-23.

18 Mizutani M, Hara M, Fujita H, Aoki J, Kanamori H, Ohashi K, et al. Comparable outcomes between autologous and allogeneic transplant for adult acute myeloid leukemia in first CR. Bone Marrow Transplant. 2016 May;51(5):645-53.

19 Messerer D, Engel J, Hasford J, Schaich M, Ehninger G, Sauerland C, et al.; German AML Intergroup. Impact of different post-remission strategies on quality of life in patients with acute myeloid leukemia. Haematologica. 2008 Jun;93(6):826-33.

20 Appelbaum FR. Alternative donor transplantation for adults with acute leukemia. Best Pract Res Clin Haematol. 2014 Sep-Dec;27(34):272-7.

21 Buckley SA, Appelbaum FR, Walter RB. Prognostic and therapeutic implications of minimal residual disease at the time of transplantation in acute leukemia. Bone Marrow Transplant. 2013 May;48(5):630-41.

22 Zuckerman T, Beyar-Katz O, Rowe JM. Should autotransplantation in acute myeloid leukemia in first complete remission be revisited? Curr Opin Hematol. 2016 Mar;23(2): 88-94.

23 Ganzel C, Rowe JM. Revisiting autologous transplantation in acute myeloid leukemia. Curr Opin Hematol. 2018 Mar;25(2):95-102.

24 Tierney JF, Stewart LA, Ghersi D, Burdett S, Sydes MR. Practical methods for incorporating summary time-to-event data into metaanalysis. Trials. 2007 Jun;8(1):16.
25 Burnett AK, Wheatley K, Goldstone AH, Stevens R, Hann I, Hills RK. Long-term results of the MRC AML10 trial. Clin Adv Hematol Oncol. 2006 Jun;4(6):445-51.

26 Esteve J, Labopin M, Pratcorona M, et al. Allogeneic hematopoietic stem-cell transplantation (HSCT) in first complete remission is superior compared to chemotherapy/autologous HSCT in patients with intermediate-risk cytogenetics acute myeloid leukemia lacking mutations in NPM1, FLT3-ITD, and CEBPA: A joint study of AMLSG, cetlam and acute leukemia working party of EBMT. Blood. 2014;124:324.

27 Visani G, Bernasconi P, Boni M, Castoldi GL, Ciolli S, Clavio M, et al. The prognostic value of cytogenetics is reinforced by the kind of induction/consolidation therapy in influencing the outcome of acute myeloid leukemiaanalysis of 848 patients. Leukemia. 2001 Jun; 15(6):903-9.

28 Zhai X, Xuan L, Sun J, et al. Autologous HSCT followed by immunotherapy and maintenance chemotherapy compared with allogeneic HSCT for intermediate-risk molecules/ cytogenetics acute myeloblastic leukemia in first complete remission. Blood. 2014;124: 3949.

29 Gorin NC, Labopin M, Piemontese S, Arcese W, Santarone S, Huang H, et al.; Acute Leukemia Working Party of the European Society for Blood and Marrow Transplantation. Tcell-replete haploidentical transplantation versus autologous stem cell transplantation in adult acute leukemia: a matched pair analysis. Haematologica. 2015 Apr;100(4):558-64.

30 Versluis J, In 't Hout FE, Devillier R, van Putten WL, Manz MG, Vekemans MC, et al. Comparative value of post-remission treatment in cytogenetically normal AML subclassified by NPM1 and FLT3-ITD allelic ratio. Leukemia. 2017 Jan;31(1):26-33.

31 Yao J, Zhang G, Liang C, Li G, Chen X, Ma Q, et al. Combination of cytogenetic classification and MRD status correlates with outcome of autologous versus allogeneic stem cell transplantation in adults with primary acute myeloid leukemia in first remission. Leuk Res. 2017 Apr;55:97-104.

32 Saraceni F, Labopin M, Gorin NC, Blaise D, Tabrizi R, Volin L, et al.; Acute Leukemia Working Party (ALWP) of the European society for Blood and Marrow Transplantation (EBMT). Matched and mismatched unrelated donor compared to autologous stem cell transplantation for acute myeloid leukemia in first complete remission: a retrospective, propensity score-weighted analysis from the ALWP of the EBMT. J Hematol Oncol. 2016 Sep;9(1):79. 
33 Suciu S, Mandelli F, de Witte T, Zittoun R, Gallo E, Labar B, et al.; EORTC and GIMEMA Leukemia Groups. Allogeneic compared with autologous stem cell transplantation in the treatment of patients younger than 46 years with acute myeloid leukemia (AML) in first complete remission (CR1): an intention-totreat analysis of the EORTC/GIMEMAAML-10 trial. Blood. 2003 Aug; 102(4): 1232-40.

34 Cho BS, Kim JH, Yoon JH, Shin SH, Yahng SA, Lee SE, et al. Superior transplantation outcomes of 8/8-matched unrelated donors as well as matched siblings to autologous transplantation for acute myeloid leukemia with intermediate cytogenetics in first remission. Eur J Haematol. 2013 May;90(5):365-74.

35 Mizutani M, Takami A, Hara M, Mizuno S, Yanada M, Chou T, et al. Comparison of Autologous and Unrelated Transplants for Cytogenetically Normal Acute Myelogenous Leukemia. Biol Blood Marrow Transplant. 2017 Sep;23(9):1447-54.

36 Grimwade D, Walker H, Oliver F, Wheatley K, Harrison C, Harrison G, et al.; The Medical Research Council Adult and Children's Leukaemia Working Parties. The importance of diagnostic cytogenetics on outcome in AML: analysis of 1,612 patients entered into the MRC AML 10 trial. Blood. 1998 Oct;92(7): 2322-33.

37 Döhner K, Schlenk RF, Habdank M, Scholl C, Rücker FG, Corbacioglu A, et al. Mutant nucleophosmin (NPM1) predicts favorable prognosis in younger adults with acute myeloid leukemia and normal cytogenetics: interaction with other gene mutations. Blood. 2005 Dec;106(12):3740-6.

38 Lin PH, Lin CC, Yang HI, Li LY, Bai LY, Chiu $\mathrm{CF}$, et al. Prognostic impact of allogeneic hematopoietic stem cell transplantation for acute myeloid leukemia patients with internal tandem duplication of FLT3. Leuk Res. 2013 Mar;37(3):287-92.
39 Bornhäuser M, Illmer T, Schaich M, Soucek S, Ehninger G, Thiede C; AML SHG 96 study group. Improved outcome after stem-cell transplantation in FLT3/ITD-positive AML. Blood. 2007 Mar; 109(5):2264-5.

40 Meshinchi S, Arceci RJ, Sanders JE, Smith FO, Woods WB, Radich JP, et al. Role of allogeneic stem cell transplantation in FLT3/ITDpositive AML. Blood. 2006 Jul;108(1):400-1.

41 Terwijn M, van Putten WL, Kelder A, van der Velden VH, Brooimans RA, Pabst T, et al. High prognostic impact of flow cytometric minimal residual disease detection in acute myeloid leukemia: data from the HOVON/ SAKK AML 42A study. J Clin Oncol. 2013 Nov;31(31):3889-97.

42 Vidriales MB, Pérez-López E, Pegenaute C, Castellanos M, Pérez JJ, Chandía M, et al.; PETHEMA Programa para el Estudio de la Terapéutica en Hemopatías Malignas Cooperative Study Group. Minimal residual disease evaluation by flow cytometry is a complementary tool to cytogenetics for treatment decisions in acute myeloid leukaemia. Leuk Res. 2016 Jan;40:1-9.

43 Buccisano F, Maurillo L, Del Principe MI, Del Poeta G, Sconocchia G, Lo-Coco F, et al. Prognostic and therapeutic implications of minimal residual disease detection in acute myeloid leukemia. Blood. 2012 Jan;119(2): 332-41.

44 Gorello P, Cazzaniga G, Alberti F, Dell'Oro MG, Gottardi E, Specchia G, et al. Quantitative assessment of minimal residual disease in acute myeloid leukemia carrying nucleophosmin (NPM1) gene mutations. Leukemia. 2006 Jun;20(6):1103-8.

45 Messina C, Candoni A, Carrabba MG, Tresoldi C, Sala E, Tassara M, et al. Wilms' tumor gene 1 transcript levels in leukapheresis of peripheral blood hematopoietic cells predict relapse risk in patients autografted for acute myeloid leukemia. Biol Blood Marrow Transplant. 2014 Oct;20(10):1586-91.
46 Abdul Wahid SF, Ismail NA, Mohd-Idris MR, Jamaluddin FW, Tumian N, Sze-Wei EY, et al. Comparison of reduced-intensity and myeloablative conditioning regimens for allogeneic hematopoietic stem cell transplantation in patients with acute myeloid leukemia and acute lymphoblastic leukemia: a meta-analysis. Stem Cells Dev. 2014 Nov;23(21):253552.

47 Stein AS, O'Donnell MR, Chai A, Schmidt GM, Nademanee A, Parker PM, et al. In vivo purging with high-dose cytarabine followed by high-dose chemoradiotherapy and reinfusion of unpurged bone marrow for adult acute myelogenous leukemia in first complete remission. J Clin Oncol. 1996 Aug;14(8):220616.

48 Czerw T, Labopin M, Gorin NC, Giebel S, Blaise D, Meloni G, et al. Long-term followup of patients with acute myeloid leukemia surviving and free of disease recurrence for at least 2 years after autologous stem cell transplantation: A report from the Acute Leukemia Working Party of the European Society for Blood and Marrow Transplantation. Cancer. 2016 Jun;122(12):1880-7.

49 Foran JM, Pavletic SZ, Logan BR, AgoviJohnson MA, Pérez WS, Bolwell BJ, et al. Unrelated donor allogeneic transplantation after failure of autologous transplantation for acute myelogenous leukemia: a study from the center for international blood and marrow transplantation research. Biol Blood Marrow Transplant. 2013 Jul;19(7):1102-8.

50 Williams BA, Wang XH, Keating A. Clonogenic assays measure leukemia stem cell killing not detectable by chromium release and flow cytometric cytotoxicity assays. Cytotherapy. 2010 Nov;12(7):951-60. 